\title{
Astaxanthin Recovery from Shrimp Residue by Solvent Ethanol Extraction Using Choline Chloride:Glycerol Deep Eutectic Solvent as Adjuvant
}

\author{
Cleidijane A. dos Santos, ${ }^{a}$ Carlos E. A. Padilha, ${ }^{b}$ Karla S. F. S. C. Damasceno, ${ }^{a}$ \\ Pedro I. P. Leite, ${ }^{c}$ Ana C. J. de Araújo, ${ }^{d}$ Priscila R. Freitas, ${ }^{d}$ Érica A. Vieira, ${ }^{e}$ \\ Angela M. T. M. Cordeiro, ${ }^{e}$ Francisco C. de Sousa Jr. ${ }^{\oplus a, c}$ and Cristiane F. de Assis ${ }^{\oplus *, a, c}$ \\ aPrograma de Pós-Graduação em Nutrição, Centro de Ciências da Saúde, \\ Universidade Federal do Rio Grande do Norte, 59078-970 Natal-RN, Brazil \\ ${ }^{b}$ Departamento de Engenharia Química, Centro de Ciências Exatas e da Terra, \\ Universidade Federal do Rio Grande do Norte, 59078-970 Natal-RN, Brazil \\ 'Departamento de Farmácia, Centro de Ciências da Saúde, \\ Universidade Federal do Rio Grande do Norte, 59078-970 Natal-RN, Brazil \\ ${ }^{d}$ Departamento de Biologia Química, Universidade Regional do Cariri, Pimenta, \\ 63105-010 Crato-CE, Brazil \\ ePrograma de Pós-Graduação em Ciências e Tecnologia de Alimentos, Centro de Tecnologia, \\ Universidade Federal da Paraíba, 58051-900 João Pessoa-PB, Brazil
}

\begin{abstract}
The present study investigated the use of choline chloride:glycerol deep eutectic solvent as an adjuvant for tuning the ethanol extraction of astaxanthin from Litopenaeus vannamei processing residues. The adjuvant concentration did not show a clear trend on the total carotenoid, however, the addition of adjuvant proved to be advantageous in the ultrasound-assisted experiments. In order to establish a balance between total carotenoid and productivity, an operational condition with ultrasound, $5 \%(\mathrm{~m} / \mathrm{v})$ choline chloride:glycerol and $10 \mathrm{~min}$ of incubation was selected, which provided $737.69 \mu \mathrm{g} \mathrm{g}^{-1}$ total carotenoids and $32.71 \mu \mathrm{g} \mathrm{g}^{-1}$ astaxanthin. When compared to the astaxanthin standard, the shrimp residue extract obtained greater antioxidant activity in free radical scavenging tests. In addition, the shrimp residue extract dramatically reduced the dosage of norfloxacin (up to $87.5 \%$ ) and gentamicin (up to $75.0 \%$ ) antibiotics in tests to inhibit the growth of Gram-negative bacteria.
\end{abstract}

Keywords: Litopenaeus vannamei, carotenoid, ultrasound, antioxidant activity

\section{Introduction}

Brazilian shrimp production is increasing significantly, and the Northeast region is the main producer of the Litopenaeus vannamei species, being responsible for $98 \%$ of the national production. ${ }^{1}$ Coupled with this high production is the amount of waste which is generated as a result of improving the species. ${ }^{2}$ These residues are formed by the shell and cephalothorax, and can correspond to $50-60 \%$ of the crustacean weight. ${ }^{3}$ In places where there is no effective environmental inspection, the waste residues are clandestinely disposed of in seas and rivers or buried, causing great environmental impact. ${ }^{4}$ Shrimp residues can

*e-mail: cristianeassis@hotmail.com be used by industry, as they are sources of compounds which have technological applications such as chitin, lipids and carotenoids, including astaxanthin. ${ }^{2,5,6}$

Astaxanthin is a carotenoid pigment naturally present in food (Figure 1). Astaxanthin has a long carbon chain skeleton with a series of conjugated carbon-carbon double bonds, which endow it with a red color and antioxidant activity. It contains a $\beta$-ionone ring and a polyunsaturated conjugated double bond, which has a strong ability to quench singlet oxygen and is a strong scavenger of reactive oxygen species. ${ }^{7}$

Its molecule has 40 carbon atoms in its structure, in which two ionone rings are arranged at the end of the molecule. ${ }^{8}$ Astaxanthin is often found in shrimp in a form associated with protein (carotenoproteins). ${ }^{9}$ 




Figure 1. Astaxanthin structure.

The antioxidant activity of astaxanthin is superior to that of other carotenoids due to its peculiar structure, being capable of exercising beneficial properties to the organism which include: immunomodulatory, anticancer, and antidiabetes properties, and prevents cardiovascular diseases and cataracts. ${ }^{10}$ A number of recent studies ${ }^{11,12}$ have involved supercritical extraction for astaxanthin recovery. Despite being an environmentally friendly technology, it achieves unsatisfactory yields and requires a high operating cost, ${ }^{13}$ so solvent extraction is still an important way to recover astaxanthin from shrimp residue. The use of some volatile organic solvents is obviously prohibitive in astaxanthin preparations for food applications due to their recognized toxicities (e.g., hexane, acetone, methanol, etc.). ${ }^{14}$ Vegetable oils have been successfully used to recover astaxanthin from shrimp residues, reaching yields above $29.8 \mu \mathrm{g} \mathrm{g}^{-1}$, as observed by da Silva et al..$^{15}$ These results are justified by the lipophilic nature of the carotenoid, however the high viscosity of the oils (ca. 0.44-0.57 Pa s) is an innate problem in this process. ${ }^{13}$ Another disadvantage of astaxanthin preparations based on vegetable oil is the limited spectrum of foods for application, as there is an increasing demand for foods with less fat content. ${ }^{16}$

Many studies have replaced conventional solvent extraction with alternative techniques in order to maximize the astaxanthin extraction yields, which include ultrasound-assisted extraction, ${ }^{17}$ microwave-assisted extraction ${ }^{18}$ and electric pulse-assisted extraction. ${ }^{19}$ In particular, the use of ultrasound irradiation is simple and can ensure a reduction in process time, reducing the solvent volume, as well as obtain better results in comparison with conventional solvent extraction..$^{20}$ Deep eutectic solvents (DES) are a new class of green solvents and are considered to be analogous to ionic liquids due to their tunable polarity. ${ }^{21,22}$ Despite this, it is worth considering that the preparation of DES is simple and ecofriendly compared to the synthesis of ionic liquids. ${ }^{21,22} \mathrm{DES}$ are formed from the mixture between hydrogen-binding donor substances and hydrogen-binding receptor substances, most of which are based on choline chloride, a quaternary ammonium salt. ${ }^{23} \mathrm{DES}$ are biodegradable and often have low toxicity and low vapor pressure, so their use has been encouraged in carotenoid extraction processes. ${ }^{24,25}$ DES extraction data for astaxanthin recovery from shrimp residues are scarce, only being explored by Zhang et al. ${ }^{26}$ The authors proposed replacing ethanol absolute with DES as a solvent, in which it was possible to achieve an increase of up to $43.1 \%$ in astaxanthin yield using shrimp residue as a solid matrix. However, like vegetable oils, extracting phases rich in DES have high viscosity, which reduces the performance in extractions caused by the limitations of mass transfer. ${ }^{21,27}$ This observation makes the need for investigations on the effect of low DES dosages on the recovery of natural compounds, especially astaxanthin from shrimp residue.

Thus, the present work proposes an extraction method assisted by choline chloride:glycerol DES and ultrasound to recover astaxanthin from L. vannamei shrimp residue. Choline chloride and choline chloride:glycerol were used as adjuvants for tuning ethanolic extraction and their effects were evaluated on the total carotenoid and astaxanthin yields. In addition, the impact of operational conditions was investigated on the quality of fatty acids present in shrimp residue extracts. Free radical scavenging tests and antibiotic modulating activity tests were carried out to evaluate the bioactive properties of the shrimp residue extract, and their results were compared with synthetic astaxanthin.

\section{Experimental}

\section{Chemicals and reagents}

Ethanol absolute, hydrochloric acid, sodium hydroxide, glycerol were purshased from Synth (São Paulo, Brazil). 2,2-Diphenyl-1-picrylhydrazyl (DPPH), acetonitrile, dichloromethane and methanol were purshased from Sigma-Aldrich (Saint Louis, MO, USA). Choline chloride was purchased from Isofar (Rio de Janeiro, Brazil) for DES synthesis. Astaxanthin was purchased from SigmaAldrich (Saint Louis, MO, USA) and was used as a standard. Sanitary water (sodium hypochlorite solution) was purchased from a local market and deionized water was prepared using the Milli-Q system (Waltham, MA, USA).

\section{Preparation of shrimp waste powder}

Shrimp residues of the Litopenaeus vannamei species were kindly provided by the Enseg Indústria Alimentícia Ltda. company, which is located in the city of Macaíba (Rio Grande do Norte, Brazil). The material was promptly washed with tap water and then immersed in a hypochlorite solution at $220 \mathrm{ppm}$ for $15 \mathrm{~min}$. After another washing step, the shrimp residues were placed in a TE394/2 air circulation oven (Tecnal, Piracicaba, Brazil) at $70{ }^{\circ} \mathrm{C}$ for $8 \mathrm{~h}$ and then crushed in a blender and stored in plastic bags. 


\section{Solvent extraction of astaxanthin from shrimp waste powder}

The astaxanthin extraction experiments obtained from shrimp residue were performed using ethanol as an extracting agent and DES as adjuvant. DES was prepared from the mixture between choline chloride (hydrogen bond acceptor) and glycerol (hydrogen bond donor) in a 1:2 molar ratio according to Cai et al. ${ }^{21}$ The mixture was heated in a thermostatic bath at $60{ }^{\circ} \mathrm{C}$ for $60 \mathrm{~min}$ and then stored in flasks with cap inside the desiccator. The DES formed was called choline chloride:glycerol. Stock solutions of choline chloride and choline chloride:glycerol were prepared from the dilution using absolute ethanol. The stock solutions were also stored in flasks with cap inside the desiccator for future use.

The extraction experiments were carried out in test tubes containing $0.2 \mathrm{~g}$ of shrimp residue powder and $2.0 \mathrm{~mL}$ of solvent extraction, which varied from $1-5 \%$ $(\mathrm{m} / \mathrm{v})$ choline chloride:glycerol. Control experiments were carried out using only absolute ethanol (without adjuvant) or $1-5 \%(\mathrm{~m} / \mathrm{v})$ choline chloride as the solvent extraction. The tubes were incubated in a L-200 thermostatic bath (Schuster, Goiânia, Brazil) with/without ultrasound $(50 / 60 \mathrm{~Hz})$ for 10,30 and $50 \mathrm{~min}$. All tubes were covered for protection from light. Then, the mixture was separated in a SL-706 centrifuge (Solab, Piracicaba, Brazil) at $6,000 \times \mathrm{g}$ for $5 \mathrm{~min}$ and the supernatant was diluted with ethanol for further analysis.

\section{Total carotenoid content}

The operational extraction conditions were screened in order to maximize the total carotenoid, which were determined after absorbance measurement in a Genesys 10uv/Vis spectrophotometer (ThermoSpectronic, Alexandria, VA, USA) at $450 \mathrm{~nm}$. Absorbance values of ethanol and ethanol with adjuvants were also recorded (control samples). The calculation of the total carotenoid was performed using equation 1 :

Carotenoid yield $\left(\mu \mathrm{g} \mathrm{g}^{-1}\right)=\frac{19.345 \times \mathrm{A} \times \mathrm{V} \times \mathrm{D}}{\mathrm{W}}$

where $\mathrm{A}$ is the absorbance value, $\mathrm{V}$ is the liquid phase volume (in $\mathrm{mL}$ ), $\mathrm{D}$ is the dilution factor used and $\mathrm{W}$ is the weight of shrimp residue powder (in $\mathrm{g}$ ). The value 19.345 is the slope of the calibration curve at $450 \mathrm{~nm}$ using astaxanthin as standard (determination coefficient, $\left.\mathrm{R}^{2}=0.993\right)$. It converts the absorbance value to $\mu \mathrm{g} \mathrm{mL^{-1 }}$ astaxanthin.
High performance liquid chromatography (HPLC) astaxanthin content

After selecting some operational conditions, the astaxanthin concentration was determined by high performance liquid chromatography (HPLC). The analysis was performed on the Shimadzu platform coupled with SPD-10AV detector (Shimadzu, Kyoto, Japan) and a Shimpack CLC-ODS (M) C18 column (Shimazu, Kyoto, Japan) with a size of $4.6 \times 150 \mathrm{~mm}$. The mobile phase was prepared from the mixture between dichloromethane, acetonitrile and methanol (70:20:10, v:v:v). ${ }^{27}$ Isocratic elution was carried out at $1.0 \mathrm{~mL} \mathrm{~min}^{-1}$ and absorbance readings were performed at $450 \mathrm{~nm}$. The astaxanthin calibration curve was previously prepared using concentrations of 0.05-30 $\mu \mathrm{g} \mathrm{mL}^{-1}\left(y\left(\mu \mathrm{g} \mathrm{mL}^{-1}\right)=132821 \times\right.$ area -9565.6 , $\left.\mathrm{R}^{2}=0.97\right)$. The analyzed samples were pre-filtered with a $0.22 \mu \mathrm{m}$ membrane and the results were obtained after three replicates.

Determination of fatty acid profile using gas chromatographymass spectrometry (GC-MS) and evaluation of extract profile using Fourier transform infrared spectroscopy

An analysis of the fatty acid profile and infrared spectroscopy by Fourier transform infrared spectroscopy (FTIR) were performed in order to obtain other characteristics of the shrimp residue extracts. The fatty acid profile was determined via the formation of fatty acid methyl esters, as described by Hartman and Lago. ${ }^{28}$ The determination of fatty acid was adapted from a report of the literature. ${ }^{29}$ The quantification was performed by normalization of the peak areas and the identification by the mass spectra database library (NIST), using a GCMS-QP2010 (Shimadzu, Kyoto, Japan) equipped with a Durabound DB-23 column $(30 \times 0.25 \mathrm{~mm} \times 0.25 \mu \mathrm{m})$. The injection port and detector temperature were fixed at $230{ }^{\circ} \mathrm{C}$ while the column temperature was set at $90^{\circ} \mathrm{C}$. The elution gradient in the column was 90 to $150{ }^{\circ} \mathrm{C}\left(10{ }^{\circ} \mathrm{C} \mathrm{min}-1\right)$, 150 to $200{ }^{\circ} \mathrm{C}\left(2{ }^{\circ} \mathrm{C} \mathrm{min}^{-1}\right), 200$ to $230{ }^{\circ} \mathrm{C}\left(10{ }^{\circ} \mathrm{C} \mathrm{min}^{-1}\right)$ in a total run of $42 \mathrm{~min}$ with a split of 100 . The carrier gas was He. ${ }^{29}$

Choline chloride:glycerol, synthetic astaxanthin and extract astaxanthin were homogenized in potassium bromide $(\mathrm{KBr})$, macerated, and pressed into pellets. Subsequently, they were recorded in transmittance and medium infrared region, from 400 to $4000 \mathrm{~cm}^{-1}$. The Shimadzu (Kyoto, Japan) spectrometer, model FTIR8400S, IRAFFINITY-1 series, IRsolution software, version 1.60 , with 32 scan numbers and $4 \mathrm{~cm}^{-1}$ resolution was used. 


\section{Determination of antioxidant activity}

The antioxidant potential of shrimp residue extracts in the best condition was evaluated based on the ability to sequester the DPPH radical according to Brand-Williams, ${ }^{30}$ but using microplate. For the DPPH assay, the microplate wells were filled with $200 \mu \mathrm{L}$ of DPPH ethanolic solution $(60 \mathrm{mM})$ and $40 \mu \mathrm{L}$ of the astaxanthin standard (125 $\mu \mathrm{g} \mathrm{mL}^{-1}$ ) or extract (125 $\mu \mathrm{g} \mathrm{mL}^{-1}$ ) or choline chloride:glycerol $(5 \% \mathrm{~m} / \mathrm{v})$. Next, the microplate was left in a dark environment for 25 min and absorbance values were obtained in an ELX800 microplate reader (BioTek Instruments, Winooski, VT, USA) up to $515 \mathrm{~nm}$. The radical scavenging percentage was calculated from the difference between the absorbance values of the control $\left(\mathrm{A}_{\text {control }}\right)$ and the absorbance of the sample $\left(\mathrm{A}_{\text {sample }}\right)$, according to equation 2 .

Radical scavenging $(\%)=\frac{\mathrm{A}_{\text {control }}-\mathrm{A}_{\text {sample }}}{\mathrm{A}_{\text {control }}} \times 100$

\section{Determination of antibiotic modulating activity}

Antimicrobial activity tests were carried out in order to assess the modulating ability of the shrimp residue extract for antibiotic dosage, which was expressed in terms of minimum inhibitory concentration (MIC). Multidrug-resistant bacterial strains (Escherichia coli 06, Staphylococcus aureus 10 and Pseudomonas aeruginosa 24) were kindly provided by the Regional University of Cariri, located in the city of Crato (Ceará, Brazil). The propagation of the bacteria was carried out in brain heart infusion (BHI) under $37^{\circ} \mathrm{C}$ for $24 \mathrm{~h}$. Next, the suspensions of each bacterium were diluted with BHI medium and placed in the microplate wells. Norfloxacin and gentamicin antibiotics were added to the test and their inhibitory effects were investigated in the absence/presence of shrimp residue extract. Both concentrations of antibiotics and shrimp residue extracts were fixed at $1024 \mu \mathrm{g} \mathrm{mL}{ }^{-1}$. A positive control was also conducted from the mixture between inoculum and BHI medium free of antibiotics and shrimp residue extract. The bacterial growth inhibition degree was assessed using the sodium resazurin method, as described by Mann and Markham ${ }^{31}$ and Palomino et al. ${ }^{32}$

\section{Statistical analysis}

The results of the tests for solvent extraction, HPLC, antioxidant activity and antibiotic modulating activity were expressed in terms of arithmetic mean and standard deviation. The significance of the effects in each study was assessed by analysis of variance (ANOVA), in which solvent extraction and antioxidant activity used the Tukey post-hoc test and the antibiotic modulating activity used the Bonferroni post-hoc test. All statistical analyzes were performed using Statistica software, ${ }^{33}$ with a $95 \%$ confidence level $(p<0.05)$.

\section{Results and Discussion}

Effect of adjuvant concentration, cavitation and incubation time on astaxanthin recovery

Figure 2 illustrates the effects of the solvent extraction operational conditions on the total carotenoid values obtained from shrimp residue.

As expected, experiments under longer incubation times generally achieved higher yield values for total carotenoids. This effect is widely reported in solvent extraction studies ${ }^{27}$ as it encourages the solute to migrate from the solid to the liquid phase. A temperature of $60{ }^{\circ} \mathrm{C}$ was selected in our studies to reduce the viscosity of the liquid phase, as well as to increase the fluid percolation on the solid matrix. However, it is important to highlight the occurrence of carotenoid loss and oxidation when samples are exposed to oxygen and/or high temperatures $\left(>60^{\circ} \mathrm{C}\right)$. An increase in the total carotenoid was observed in the experiment without ultrasound and without adjuvant from 288.24 to $470.08 \mu \mathrm{g} \mathrm{g}^{-1}$ in the time from 10 to $30 \mathrm{~min}$, however the yield was reduced to only $325.64 \mu \mathrm{g} \mathrm{g}^{-1}$ after $50 \mathrm{~min}$.

Ultrasound-assisted experiments showed higher total carotenoid except for some conditions using $30 \mathrm{~min}$ of incubation. Using ultrasound for $50 \mathrm{~min}$ increased the recovery of total carotenoids by $512.7,145.0$ and $205.9 \%$ using 1, 2 and $5 \%(\mathrm{~m} / \mathrm{v})$ choline chloride, respectively. In particular, this technique achieved a total carotenoid equal to $737.69 \mu \mathrm{g} \mathrm{g}^{-1}$ at the condition of $5 \%(\mathrm{~m} / \mathrm{v})$ choline chloride:glycerol and $10 \mathrm{~min}$, which represents an increase of $289.4 \%$ compared to the experiment without ultrasound. It is noteworthy that this condition obtained a similar total carotenoid to experiments with 30 and $50 \mathrm{~min}$. The use of ultrasound has been explored for years to improve the solvent extraction performance, which includes carotenoid recovery studies. ${ }^{27,34,35}$ The emission of high frequency pulses on the extractor leads to cavitational bubbles forming. When these bubbles collapse near surfaces they can cause cell disruption as well as solid comminution, which positively affects mass transfer. ${ }^{36,37}$

Adjuvants have often been used to increase the yield and selectivity of proteins and phenolic compounds in extraction processes, ${ }^{27,38,39}$ but there are a limited number of reports on their role in carotenoid recovery. 


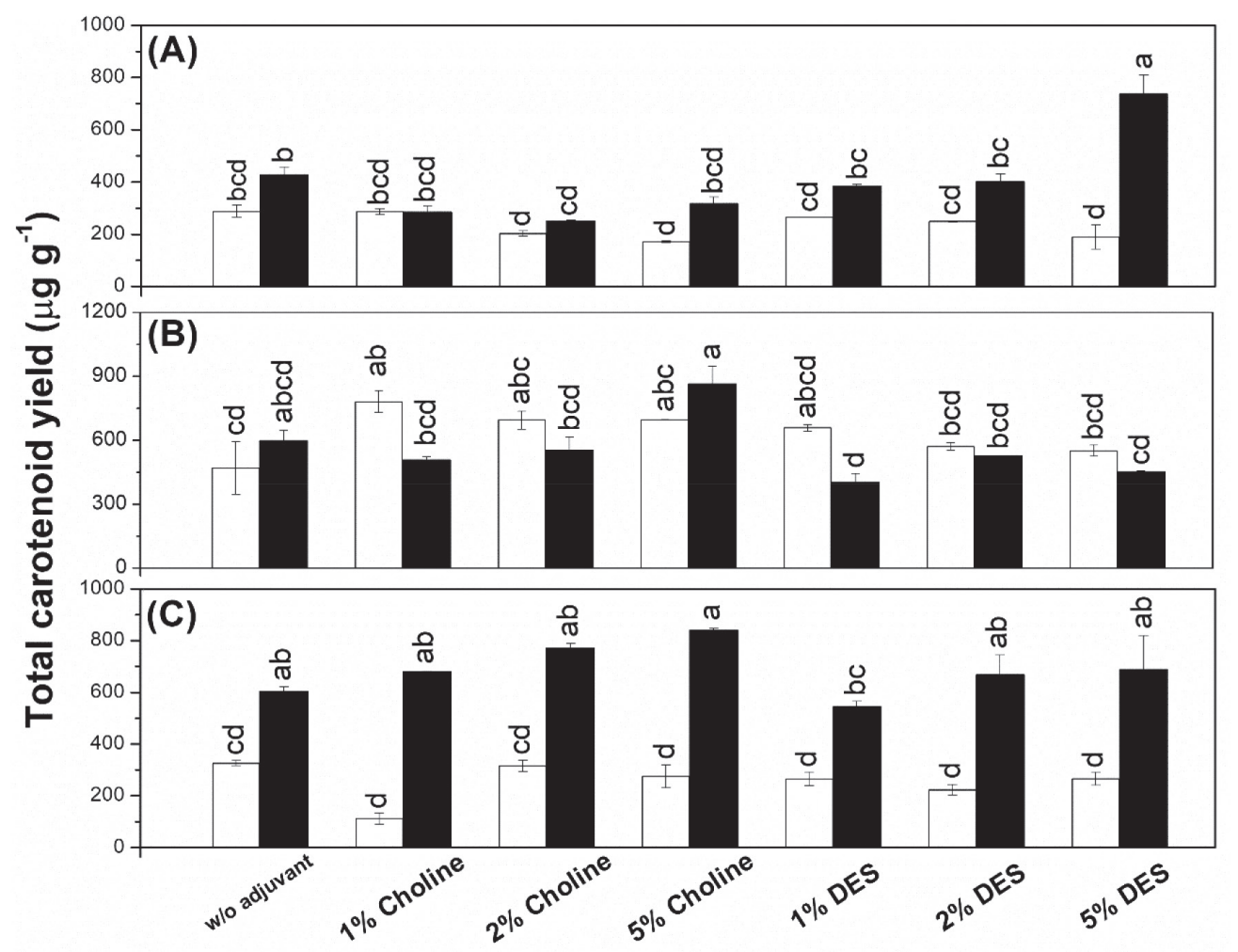

Figure 2. Total carotenoid extraction yield $\left(\mu \mathrm{g} \mathrm{g}^{-1}\right)$ from the shrimp residue powder using ethanol-adjuvant mixtures in a thermostatic bath (white bar) and thermostatic bath with ultrasound assistance (black bar) in the incubation times of 10 (A), 30 (B) and $50 \mathrm{~min}(\mathrm{C})$. The other operational conditions for the extraction were: $0.2 \mathrm{~g}$ of shrimp residue powder, $2.0 \mathrm{~mL}$ of liquid phase and a temperature of $60^{\circ} \mathrm{C}$. The letters a, b, c and d were used to compare the total carotenoid values at fixed exposure time. Same letter conditions indicate that there is no significant difference between them $(p>0.05)$.

Lee and Row $^{24}$ reported that the addition of ionic liquids and DES as adjuvants had a positive impact on astaxanthin recovery by extraction of marine plants. In turn, the effects of the adjuvant concentration in the present study showed double trends in the total carotenoid. The increase in the adjuvant concentration was generally detrimental to the total carotenoid in experiments without ultrasound. Despite not showing significant differences $(p>0.05)$, increasing the choline chloride concentration from 1 to $5 \%(\mathrm{~m} / \mathrm{v})$ reduced the total carotenoid from 780.9 to $695.8 \mu \mathrm{g} \mathrm{g}^{-1}$ in experiments with $30 \mathrm{~min}$ of incubation. The total carotenoid decreased by $28.4 \%$ under $10 \mathrm{~min}$ of incubation, with an increase of choline chloride:glycerol concentration from 1 to $5 \%(\mathrm{~m} / \mathrm{v})$. In turn, the increase in the adjuvant concentration in the extraction systems enabled higher total carotenoid under conditions assisted by ultrasound. Using choline chloride as an adjuvant and $50 \mathrm{~min}$ incubation, total carotenoid progressively increased with the addition of choline chloride from 604.21 (control) to $679.65 \mu \mathrm{g} \mathrm{g}^{-1}$ for $1 \%(\mathrm{~m} / \mathrm{v})$ adjuvant, $772.51 \mu \mathrm{g} \mathrm{g}^{-1}$ for $2 \%(\mathrm{~m} / \mathrm{v})$ adjuvant and $840.22 \mu \mathrm{g} \mathrm{g}^{-1}$ for $5 \%(\mathrm{~m} / \mathrm{v})$ adjuvant. The extraction performance notoriously increased due to the increase of choline chloride:glycerol concentration from 2 to $5 \%(\mathrm{~m} / \mathrm{v})$ in the ultrasound-assisted experiments for $10 \mathrm{~min}$ of incubation.
These results are unprecedented in the literature, as it indicates possible synergism between adjuvants and ultrasound. Literature study ${ }^{40}$ has also reported that the use of DES can increase cell permeability and consequently reduce resistance to mass transfer. Thus, the shrimp residue extract prepared with ultrasound and $5 \%(\mathrm{~m} / \mathrm{v})$ choline chloride:glycerol for $10 \mathrm{~min}$ was selected for the following steps in order to obtain extracts with interesting bioactive properties and greater productivity.

The astaxanthin concentration in the shrimp residue extract was determined by HPLC, as can be seen in Figure 3.

The peak referring to standard astaxanthin (at $2.4 \mathrm{~min}$ ) is evident in the shrimp residue extract, however it is possible to observe the presence of other peaks. López-Cervantes et al. ${ }^{41}$ and $\mathrm{Hu}$ et al ${ }^{17}$ attributed this behavior to the presence of astaxanthin isomers in extracts obtained from shrimp residues. Table 1 shows the values of astaxanthin yield of different shrimp residue extracts.

The extract obtained from extraction with ultrasound and $5 \%(\mathrm{~m} / \mathrm{v})$ choline chloride:glycerol for $10 \mathrm{~min}$ reached a higher average astaxanthin value $\left(32.71 \mu \mathrm{g} \mathrm{g}^{-1}\right)$ than extracts obtained in experiments involving only ethanol $\left(30.99 \mu \mathrm{g} \mathrm{g}^{-1}\right)$ or ethanol mixture choline chloride $\left(23.73 \mu \mathrm{g} \mathrm{g}^{-1}\right)$ as a liquid phase. These results highlight 


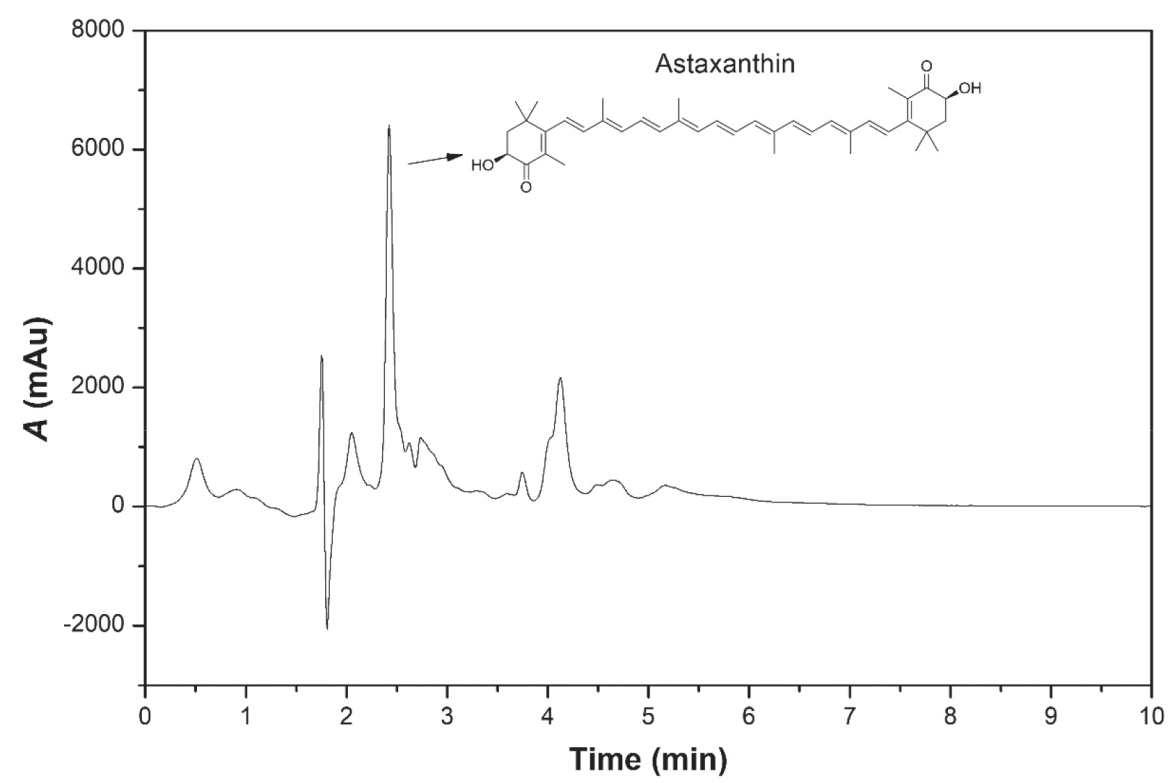

Figure 3. HPLC profile of shrimp residue extract obtained from ultrasound-assisted extraction using $5 \%(\mathrm{~m} / \mathrm{v})$ choline chloride:glycerol and $10 \mathrm{~min}$ incubation.

Table 1. Astaxanthin recovered from shrimp residue powder under different operating conditions

\begin{tabular}{lc}
\hline Operational conditions & Astaxanthin $/\left(\mu \mathrm{g} \mathrm{g}^{-1}\right)$ \\
\hline $\begin{array}{l}\text { Only ethanol, without ultrasound treatment, } \\
30 \mathrm{~min} \text { of incubation time }\end{array}$ & $30.99 \pm 0.52^{\mathrm{a}}$ \\
$5 \%(\mathrm{~m} / \mathrm{v})$ DES, with ultrasound treatment, & $32.71 \pm 0.72^{\mathrm{a}}$ \\
$10 \mathrm{~min}$ of incubation time & \\
$5 \%(\mathrm{~m} / \mathrm{v})$ chloride choline, with ultrasound & $23.73 \pm 1.50^{\mathrm{b}}$ \\
\hline treatment, 30 min of incubation time & \\
\hline
\end{tabular}

The letters a and $b$ were used to compare the recovered astaxanthin values. Same letter conditions indicate that there is no significant difference between them $(p>0.05)$. DES: deep eutectic solvent.

the role of choline chloride:glycerol as an adjuvant in astaxanthin recovery. In fact, Seabra et al. ${ }^{6}$ obtained an astaxanthin yield equal to $98.51 \mu \mathrm{g} \mathrm{g}^{-1}$ from dry Litopenaeus vannamei residue. However, the authors used a mixture of hexane and isopropanol (60:40) as a liquid phase, which limits the number of applications of recovered astaxanthin when compared to the present study.

FTIR analyzes were performed to confirm the presence of astaxanthin in the shrimp residue extract. Characteristic bands of the synthetic astaxanthin are also present in the FTIR spectrum of the shrimp residue extract in Figure 4, such as the band related to the deformation of the methyl group $\left(1047 \mathrm{~cm}^{-1}\right)$ and the band related to the stretching of the hydroxyl group $\left(3323 \mathrm{~cm}^{-1}\right) .^{42}$ It is important to mention that these bands can also be attributed to the presence of fatty acids.

Slight similarities are observed between choline chloride:glycerol and the shrimp residue extract, more specifically the choline chloride $v_{\text {as }} \mathrm{COO}$ band observed at the wavelength equal to $957 \mathrm{~cm}^{-1}{ }^{43}$ The characteristic bands of the astaxanthin extract are related to the presence of fatty acids in the sample. According to Subramanian et al.$^{42}$ the relatively strong mode at $3011.3 \mathrm{~cm}^{-1}$ shows the presence of a polyunsaturated fatty acid. Therefore, the FTIR results show bands referring to astaxanthin and fatty acids, especially unsaturated ones that present groups similar to astaxanthin.

Effect of the operational conditions of solvent extraction on the fatty acid profile

In addition to astaxanthin, shrimp residues can have high levels of fat (0.8-3.5 $\mathrm{mg} \mathrm{g}^{-1}$ of material), with unsaturated fatty acids being considered as compounds with high added value. ${ }^{44}$ Consuming diets rich in unsaturated fatty acids has been associated with different beneficial effects on human health, such as reducing skin aging, ${ }^{45}$ protection against chronic diseases ${ }^{46}$ protection against cardiovascular diseases, ${ }^{47}$ and prevention of mental disorders, ${ }^{48}$ etc. However, unsaturated acids are more susceptible to oxidative stress, so the extraction processes must preserve the quality of the fatty acids. ${ }^{49}$ Table 2 shows the fatty acid profiles of shrimp residue extracts under different operating conditions.

It is possible to observe that there were practically no changes in the unsaturated fatty acid proportions among the extracts. The sample obtained by DES-assisted extraction had lower linoleic acid values (36.36vs. 33.79\%) compared to the extraction using only ethanol, however higher oleic acid values (27.94 vs. 30.98\%) were obtained. Gómez-Estaca et al. ${ }^{50}$ reported a similar fatty acid profile 




Figure 4. FTIR (KBr) spectra of choline chloride:glycerol (a), shrimp residue extract (b) and synthetic astaxanthin (c). The shrimp residue extract was obtained from the following conditions: $2.0 \mathrm{~mL}$ of liquid phase, $5 \%(\mathrm{~m} / \mathrm{v})$ choline chloride:glycerol, $0.2 \mathrm{~g}$ of shrimp residue powder, ultrasound $(50 / 60 \mathrm{~Hz})$ and 10 min incubation.

to the present study, in which unsaturated acids (oleic acid and linoleic acid) were also the major compounds in the Litopenaeus vannamei processing residue extract. These results reinforce the effectiveness of DES-assisted extraction for recovering bioactive compounds, as well as establishing shrimp residue extract as a potential food ingredient.

\section{Antioxidant activity of shrimp residue extract}

The antioxidant activity was performed using extracted astaxanthin and standard astaxanthin at the same concentration of $125 \mu \mathrm{g} \mathrm{mL}^{-1}$ using the DPPH radical scavenging test. The choline chloride:glycerol $(5 \% \mathrm{~m} / \mathrm{v})$ showed no antioxidant activity. The results obtained were $13.16 \pm 3.35$ and $22.65 \pm 2.90 \%$ for synthetic and extracted astaxanthin, respectively. The inhibition percentage of DPPH radical scavenging shows the greater potential of the extracted astaxanthin when compared to the synthetic astaxanthin. Liu et al..$^{51}$ performed the same antioxidant tests with different astaxanthin isomers, and according to the authors, the data corroborate the present study, with an inhibition percentage equal to $23.70 \%$ using astaxanthin concentration of $100 \mu \mathrm{g} \mathrm{mL}^{-1}$.

According to Yang et $a l . .^{52}$ the carotenoid present in the shrimp residue is astaxanthin in the form of all-trans astaxanthin, astaxanthin's mono and diesters due to the presence of fatty acids extracted during the process. Furthermore, shrimp waste extract contains other antioxidants, such as phenolics, in addition to carotenoids. ${ }^{53}$ Components other than carotenoids may be also responsible for the radical scavenging activity of extracts. However, as the activity correlated with the carotenoid content of the extract, it can be presumed that carotenoids are the major antioxidative principles in the shrimp extract. ${ }^{54}$

The antibiotic modulating activity of shrimp residue extract

Concerns about the emergence of super-resistant microorganisms have led scientists to consider the controlled use of antibiotics as well as methods of restoring antibiotic activity. ${ }^{55}$ Several studies ${ }^{55-58}$ have investigated the

Table 2. Fatty acid percentage (average values) in shrimp residue extracts obtained under different operating conditions

\begin{tabular}{|c|c|c|c|c|}
\hline \multirow{2}{*}{ Operational conditions } & \multicolumn{4}{|c|}{ Fatty acid / \% } \\
\hline & Palmitic acid (C16:0) & Estearic acid (C18:0) & Oleic acid (C18:1) & Linoleic acid (C18:2) \\
\hline $\begin{array}{l}\text { Only ethanol, without ultrasound treatment, } 30 \mathrm{~min} \\
\text { of incubation time }\end{array}$ & 29.41 & 6.29 & 27.94 & 36.36 \\
\hline $\begin{array}{l}5 \%(\mathrm{~m} / \mathrm{v}) \text { choline chloride:glycerol with ultrasound } \\
\text { treatment, } 10 \text { min of incubation time }\end{array}$ & 35.23 & - & 30.98 & 33.79 \\
\hline $\begin{array}{l}5 \%(\mathrm{~m} / \mathrm{v}) \text { chloride choline, with ultrasound } \\
\text { treatment- } 30 \text { min of incubation time }\end{array}$ & 33.60 & - & 41.32 & 25.08 \\
\hline
\end{tabular}



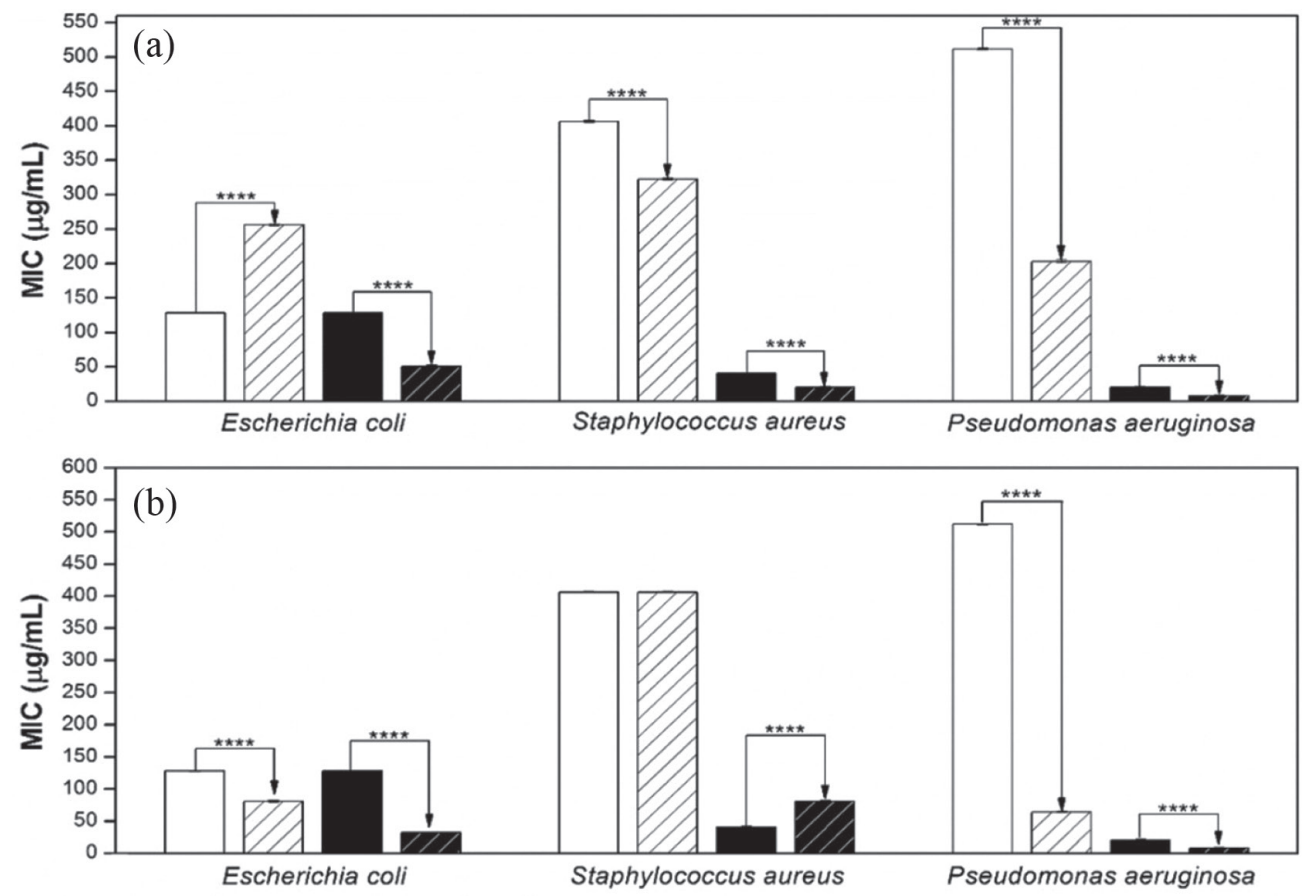

Figure 5. MIC values $\left(\mu \mathrm{g} \mathrm{mL}^{-1}\right)$ of antibiotics in bacterial growth assays in the presence of synthetic astaxanthin additives (a) and shrimp residue extract (b). The tests were carried out under the following conditions: norfloxacin (white bar), norfloxacin + synthetic astaxanthin/shrimp residue extract (white hatch bar), gentamicin (black bar) and gentamicin + synthetic astaxanthin/shrimp residue extract (black hatch bar).

contribution of natural bioactive compounds to the action mechanisms of antibiotics, but more details are needed on the antibiotic modulating activity of extracts rich in astaxanthin. Norfloxacin and gentamicin antibiotics were used in the present study, which acts in protein synthesis inhibition and nucleic acid metabolism inhibition, respectively.

Figure 5 shows the effects of shrimp residue extract on the antibiotic dosage in bacterial growth inhibition tests.

Except the gentamicin used to inhibit $E$. coli, the addition of synthetic astaxanthin reduced the MIC values for all investigated bacterial strains. In trials involving S. aureus, synthetic astaxanthin reduced the dosage of norfloxacin and gentamicin by 20.6 and $50.0 \%$, respectively. Astaxanthin can interact with the outer membrane of Gram-negative bacteria to increase the permeability of antibiotics and/or cause leakage of the cytoplasm. ${ }^{59}$ Ushakumari and Ramanujan ${ }^{60}$ also reported the potential of astaxanthin to inhibit $S$. aureus. When compared to synthetic astaxanthin, the use of shrimp residue extract reduced the antibiotics dosage to inhibit Gram-negative bacteria, as can be seen in Figure 5b. For example, in the assays with P. aeruginosa, the MIC value for gentamicin decreased from $203.2 \mu \mathrm{g} \mathrm{mL}^{-1}$ in the presence of synthetic astaxanthin to $64.0 \mu \mathrm{g} \mathrm{mL}^{-1}$ in the presence of shrimp residue extract. As with antioxidant activity tests, the availability of other classes of bioactive compounds in the shrimp residue extract can increase antibiotic modulating activity, as reported by Fankam et al. ${ }^{56}$ and Karpiński and Adamczak. ${ }^{59}$ In turn, the shrimp residue extract did not show a beneficial effect for inhibiting S. aureus. This fact contradicts not only the results obtained with synthetic astaxanthin (Figure 5a), but also reports ${ }^{51,61}$ which indicate a greater antimicrobial effect of carotenoids on Gram-positive bacteria than Gram-negative bacteria. The antagonistic effect that occurred in E. coli and S. aureus using synthetic and extracted astaxanthin, respectively, can be explained by two mechanisms: chelation of the antibiotic's constituents for the natural product and competition of substances for the binding site in the bacterial cell. ${ }^{62,63}$

\section{Conclusions}

High total carotenoid ( $\left.737.69 \mu \mathrm{g} \mathrm{mL}^{-1}\right)$ and astaxanthin (32.71 $\mu \mathrm{g} \mathrm{mL}^{-1}$ ) yields were obtained from the shrimp residue extraction under ultrasound conditions and $5 \%(\mathrm{~m} / \mathrm{v})$ DES. It was possible to observe the existence of synergism between ultrasound and adjuvant which enabled intensified mass transfer and consequently greater productivity. This operational condition practically did not alter the fatty acid profile, so that the content of unsaturated fatty acids is a major factor in the shrimp residue extract. When compared with synthetic astaxanthin, the percentage of DPPH radical scavenging of the shrimp residue extract reached $22.65 \pm 2.90 \%$, which represents an increase of $72 \%$. The use of shrimp residue extract provided a severe reduction in the MIC values for norfloxacin and gentamicin antibiotics in experiments 
involving Gram-negative bacteria. In summary, ethanolic extraction assisted by ultrasound and DES is an effective way to recover astaxanthin obtained from shrimp residue and enables generating extracts with potential application in the field of food and medicine.

\section{Acknowledgments}

This study was financed in part by the Coordenação de Aperfeiçoamento de Pessoal de Nível Superior Brazil (CAPES) finance code 001. The authors thank the Conselho Nacional de Pesquisas (CNPq) for financial support and Nutrition Postgraduate Program (PPGNUT/ UFRN/PROAP).

\section{Author Contributions}

Cleidijane A. Santos was responsible for the project, participated in all planning, execution, and preparation of the manuscript; Cristiane F. de Assis was advisor and supervisor of the project; Carlos E. Padilha was co-advisor and supervisor of the project, responsible for statistical analysis, revision of the text; Érica A. Vieira supervised the analysis for the determination of fatty acids; Angela M. T. M. Cordeiro and Karla S. F. S. C. Damasceno supervised the analysis of fatty acid; Pedro I. P. Leite, Ana C. J. de Araújo and Priscila R. Freitas were responsible for experiments and analysis of antimicrobial activity; Francisco C. de Sousa Jr. supervised the astaxanthin analysis on HPLC and performed the analysis of the results obtained.

\section{References}

1. Aquino, A. H. C.; Ribeiro, K.; dos Santos, D. B.; Pontes, C. S.; Rev. Campo-Território 2017, 12, 366.

2. Amiguet, V. T.; Kramp, K. L.; Mao, J.; McRae, C.; Goulah, A.; Kimpe, L. E.; Blais, J. M.; Arnason, J. T.; Food Chem. 2012, $130,853$.

3. Takeungwongtrakul, S.; Benjakul, S.; Santoso, J.; Trilaksani, W.; Nurilmala, M.; J. Food Process. Preserv. 2015, 39, 10.

4. de Figueirêdo, M. C. B.; Araújo, L. F. P.; Rosa, M. F.; de Morais, L. F. S.; Paulino, W. D.; Gomes, R. B.; Eng. Sanit. Ambient. 2006, 11, 231.

5. López-Cervantes, J.; Sanches-Silva, A. T.; Sendón, R.; PaseiroLosada, P.; Costa, H. S.; Sánchez-Machado, D. I.; Soto-Valdez, H.; Núñez-Gastélum, J. A.; Aurrekoetxea, G. P.; Angulo, I.; Grasas Aceites 2011, 62, 321.

6. Seabra, L. M. J. A. J.; Damasceno, K. S. F. S. C.; Silva, C. R.; Gomes, C. C.; Pedrosa, L. F. C.; Rev. Ceres 2014, 61, 130.

7. Schönbeck, C.; Madsen, T. L.; Peters, G. H.; Holm, R.; Loftsson, T.; Int. J. Pharm. 2017, 531, 504.
8. Martínez-Delgado, A. A.; Khandual, S.; Villanueva-Rodríguez, S. J.; Food Chem. 2017, 225, 23.

9. Prameela, K.; Venkatesh, K.; Immandi, S. B.; Kasturi, A. P. K.; Rama Krishna, C.; Mohan, C. M.; Food Chem. 2017, 237, 121.

10. Zhao, T.; Yan, X.; Sun, L.; Yang, T.; Hu, X.; He, Z.; Liu, F.; Liu, X.; Trends Food Sci. Technol. 2019, 91, 354.

11. Molino, A.; Mehariya, S.; Iovine, A.; Larocca, V.; di Sanzo, G.; Martino, M.; Casella, P.; Chianese, S.; Musmarra, D.; Mar. Drugs 2018, 16, 432.

12. Roy, V. C.; Getachew, A. T.; Cho, Y.-J. J.; Park, J.-S. S.; Chun, B.-S. S.; J. Supercrit. Fluids 2020, 159, 104773.

13. Gao, J.; You, J.; Kang, J.; Nie, F.; Ji, H.; Liu, S.; Food Chem. 2020, 325, 126850.

14. Saini, R. K.; Keum, Y.-S.; Food Chem. 2018, 240, 90.

15. da Silva, A. K. N.; Rodrigues, B. D.; da Silva, L. H. M.; Rodrigues, A. M. C.; Food Sci. Technol. 2018, 38, 454.

16. Sichieri, R.; Coitinho, D. C.; Monteiro, J. B.; Coutinho, W.; Arq. Bras. Endocrinol. Metabol. 2000, 44, 227.

17. Hu, J.; Lu, W.; Lv, M.; Wang, Y.; Ding, R.; Wang, L.; Braz. J. Pharmacog. 2019, 29, 24.

18. Fan, Y.; Niu, Z.; Xu, C.; Yang, L.; Chen, F.; Zhang, H.; Ind. Crops Prod. 2019, 141, 111809.

19. Martínez, J. M.; Gojkovic, Z.; Ferro, L.; Maza, M.; Álvarez, I.; Raso, J.; Funk, C.; Bioresour. Technol. 2019, 289, 121694.

20. Zou, T. B.; Jia, Q.; Li, H. W.; Wang, C. X.; Wu, H. F.; Mar. Drugs 2013, 11, 1644.

21. Cai, C.; Wu, S.; Wang, C.; Yang, Y.; Sun, D.; Li, F.; Tan, Z.; Sep. Purif. Technol. 2019, 209, 112.

22. Shang, X.; Dou, Y.; Zhang, Y.; Tan, J. N.; Liu, X.; Zhang, Z.; Ind. Crops Prod. 2019, 140, 111724.

23. Dai, Y.; Row, K. H.; Molecules 2019, 24, 2300.

24. Lee, Y. R.; Row, K. H.; J. Ind. Eng. Chem. 2016, 39, 87.

25. Koutsoukos, S.; Tsiaka, T.; Tzani, A.; Zoumpoulakis, P.; Detsi, A.; J. Cleaner Prod. 2019, 241, 118384.

26. Zhang, H.; Tang, B.; Row, K. H.; Anal. Lett. 2014, 47, 742.

27. Rao, A. R.; Baskaran, V.; Sarada, R.; Ravinchankar, G. A.; Food Res. Inter. 2013, 54, 711.

28. Hartman, L.; Lago, R. C. A.; Lab. Pract. 1973, 22, 475.

29. Alcântara, M.; Lima, A. A.; Braga, A. A.; Tonon, R. R.; Galdeano, M. M.; Mattos, M. M.; Brígida, A. A.; Rosenhaim, R.; Santos, N.; Cordeiro, A. A.; Powder Technol. 2019, 354, 877.

30. Brand-Williams, W.; Cuvelier, M. E.; Berset, C.; Lebensm.-Wiss. Technol. 1995, 30, 25.

31. Mann, C. M.; Markham, J. L.; J. Appl. Microbiol. 1998, 84, 538.

32. Palomino, J.-C.; Martin, A.; Camacho, M.; Guerra, H.; Swings, J.; Portaels, F.; Antimicrob. Agents Chemother. 2002, 46, 2720.

33. Statistica, version 7.0; Statsoft, USA, Tulsa, OK, 2007.

34. Gayathri, S.; Rajasree Radhika, S. R.; Suman, T. Y.; Aranganathan, L.; Biomass Convers. Biorefin. 2018, 8, 791. 
35. Sendón, R.; Costa, H. S.; Soto Valdez, H.; Aurrekoetxea, G. P.; Sanches-Silva, A.; de Quirós, A. B.; Paseiro, P.; Ribeiro, T.; Angulo, I.; Sánchez-Machado, D. I.; Albuquerque, T. G.; López-Cervantes, J.; Biomed. Chromatogr. 2012, 27, 757.

36. Chen, Y.; Truong, V. N. T. T.; Bu, X.; Xie, G.; Ultrason. Sonochem. 2019, 60, 104739.

37. Fu, X.; Belwal, T.; Cravotto, G.; Luo, Z.; Ultrason. Sonochem. 2019, 104726.

38. Neves, C. M. S. S.; Sousa, R. C. S.; Pereira, M. M.; Freire, M. G.; Coutinho, J. A. P.; Biochem. Eng. J. 2019, 141, 239.

39. Ran, L.; Yang, C.; Xu, M.; Yi, Z.; Ren, D.; Yi, L.; Sep. Purif. Technol. 2019, 226, 154.

40. da Costa, W. A.; Padilha, C. E. A.; Dantas, J. M. M.; Silva, M. M. C. L.; Rocha, H. A. O.; da Silva, F. L. H.; Ferrari, M.; dos Santos, E. S.; Bioresour. Technol. Rep. 2020, 12, 100561.

41. López-Cervantes, J.; Sánchez-Machado, D. I.; GutiérrezCoronado, M. A.; Ríos-Vázquez, N. J.; Biomed. Chromatogr. 2006, 20, 981.

42. Subramanian, B.; Thibault, M. H.; Djaoued, Y.; Pelletier, C.; Touaibia, M.; Tchoukanova, N.; Analyst 2015, 140, 7423.

43. Du, C.; Zhao, B.; Chen, X. B.; Birbilis, N.; Yang, H.; Sci. Rep. 2016, 6, 29225.

44. Brasileiro, O. L.; Cavalheiro, J. M. O.; Prado, J. P. S.; dos Anjos, A. G.; Cavalheiri, T. T. B.; Ciênc. Agrotec. 2012, 36, 189.

45. Latreille, J.; Kesse-Guyot, E.; Malvy, D.; Andreeva, V.; Galan, P.; Tschachler, E.; Hercberg, S.; Guinot, C.; Ezzedine, K.; J. Dermatol. Sci. 2013, 72, 233.

46. Abdullah, M. M. H.; Jew, S.; Jones, P. J. H.; Nutr. Rev. 2017, $75,163$.

47. Yang, W. S.; Chen, Y. Y.; Chen, P. C.; Hsu, H. C.; Su, T. C.; Lin, H. J.; Chen, M. F.; Lee, Y. T.; Chien, K. L.; Sci. Rep. 2019, 9, 19298.

48. Bentsen, H.; Microb. Ecol. Health Dis. 2017, 28, 1281916.
49. Carvalho, R. H. R.; Galvão, E. L.; Barros, J. A. C.; Conceição, M. M.; Sousa, E. M. B. D.; Braz. J. Chem. Eng. 2012, 29, 409.

50. Gómez-Estaca, J.; Calvo, M. M. M.; Álvarez-Acero, I.; Montero, P.; Gómez-Guillén, M. C. C.; Food Chem. 2017, 216, 37.

51. Liu, Z.; Sun, X.; Sun, X.; Wang, S.; Xu, Y.; J. Ocean Univ. China 2019, 18, 926.

52. Yang, S.; Zhou, Q.; Yang, L.; Xue, Y.; Xu, J.; Xue, C.; J. Oleo Sci. 2015, 64, 243.

53. Seymour, T. A.; Li, S. J.; Morrissey, M. T.; J. Agric. Food Chem. 1996, 44, 682.

54. Sowmya, R.; Sachindra, N. M.; Food Chem. 2012, 134, 308.

55. Wamba, B. E. N.; Mbaveng, A. T.; Nayim, P.; Dzotam, J. K.; Ngalani, O. J. T.; Kuete, V.; Int. J. Microbiol. 2018, 2018, 1920198.

56. Fankam, A. G.; Kuiate, J. R.; Kuete, V.; BMC Complementary Altern. Med. 2017, 17, 168.

57. Nonato, C. F. A.; Leite, D. O. D.; Pereira, R. C.; Boligon, A. A.; Ribeiro-Filho, J.; Rodrigues, F. F. G.; da Costa, J. G. M.; PeerJ 2018, 2018, e5991.

58. Oyedemi, S. O.; Oyedemi, B. O.; Prieto, J. M.; Coopoosamy, R. M.; Stapleton, P.; Gibbons, S.; S. Afr. J. Bot. 2016, 105, 337.

59. Karpiński, T. M.; Adamczak, A.; Antioxidants 2019, 8, 239.

60. Ushakumari, U. N.; Ramanujan, R.; Int. Curr. Pharm. J. 2013, 2,67 .

61. Deyab, M. A.; Abou-Dobara, M. I.; Egypt. J. Exp. Biol. 2013, 9, 281.

62. Bezerra, C. F.; Camilo, C. J.; Silva, M. K. N.; de Freitas, T. S.; Ribeiro-Filho, J.; Coutinho, H. D. M.; Microb. Pathog. 2017, $113,265$.

63. Wagner, H.; Fitoterapia 2011, 82, 34. 